\title{
CLASSIFICATION OF THE GENUS STREPTOCOCCUS
}

Report to the Subcommittee on Streptococcus at the Sixth International Congress of Microbiology, Rome, Italy,

September, 1953, by J. Howard Brown,

Johns Hopkins University, Baltimore, Maryland

Since 1915 I have been interested in the IDENTIFICATION of streptococci. I prefer the word IDENTIFICATION to CLASSIFICATION because the prerequisite of classification is identification. Unless objects are identified they cannot be classified. Classification consists in bringing together similar objects under similar names and in such a way as to indicate, if possible, natural relationships; hence, we have genera and species. If, within species, there are members showing fairly stable differences not great enough to be regarded as different species, they may be classified as varieties of the species, but in no case should they lose their identity so long as they are recognizable.

Nomenclature is the language, the vocabulary, of classification and, for its use in bacteriology, an International Bacteriological Code of Nomenclature has been adopted. Principle 1 of this code reads "The essential points in nomenclature are (1) to aim at fixity of names; (2) to avoid or to reject the use of forms and names which may cause error or ambiguity or throw science into confusion."

In suggesting that I speak on this topic Dr. Breed wrote "We always have 'splitters' and 'lumpers' with us $x \mathbf{x}^{\prime \prime}$. I immediately assumed that $I$ was a "splitter" because $I$ have favored retaining the names of certain streptococci which are either uncommon or which differ from better known species in socalled minor details, such as hemolysis, host habitat, fermentation of a few carbohydrates, serological typing, and even specific virulence, instead of "lumping" them together as possible, though inconvenient, variants of better known species. I have insisted upon maintaining their identity whether as separate species or varieties: I have needed names for them. Knowledge of their existence has led me to look for them outside of the "lump"; otherwise they would have been missed or ignored. 
In the nature of things, in botany and zoology, one expects to find more varieties than species and more species than genera. Why should it be otherwise in bacteriology? It is true that (Rule 6) "Names of species are binary combinations consisting of the name of the genus followed by a single specific epithet", but (Rule 7) "Names of subspecies (varieties) are ternary combinations consisting of the name of the genus followed by the specific and the subspecific epithets in order".

Reference should be made to the Report to the Subcommittee on Streptococcus presented to the Fifth International Congress of Microbiology in 1950 (see this BULLETIN p. 163).

Now where do I stand? If I decide that serological Group A includes several species of Streptococcus I am a "splitter"; if I include these as varieties of a single species, Streptococcus pyogenes, I am a "lumper", but not as great a "lumper" as if I were to ignore all varieties. Error, ambiguity and confusion may result from the use of too few names as well as from the use of too many names. Simplicity attempted in this way may result in complexity. Nomenclature must be adequate.

What help may we get from the "Key to the species of genus Streptococcus" in Bergey's Manual, 6th Ed.? The "Pyogenic group", with which I am mostly concerned today, is described as follows:

No growth at $10^{\circ} \mathrm{C}$. No growth at $45^{\circ} \mathrm{C}$. Generally beta hemolytic. Generally do not curdle milk and reduce litmus slowly if at all. Mannitol and glycerol generally not fermented. Not tolerant of 0.1 per cent methylene blue, 6.5 per cent $\mathrm{NaCl}$ and $\mathrm{pH} 9.6$. Produce ammonia from peptone.

It may be noted that the 11 characteristics there listed in the general dexcription 5 are doubtful or equivocal. In the following steps of the Key to the Pyogenic group there is no place for lactose negative members of serological Groups A or $\mathrm{B}$ and the only lactose negative members of Group $\mathrm{C}$ are under the designation "Lactose may or may not be fermented". There is no mention of salicin in the Key to the Pyogenic 
group although this is a critical glucoside for certain members of Serological Groups A and B. A key that fails to open so many locks is certainly not a master key.

If you examine the table on Characteristics of Various Streptococci by Swift in Bacterial and Mycotic infections of Man (Dubos, 1948 and 1952), similar discrepancies will be noted. Only one species and no varieties are indicated among the streptococci of serologic Groups A and B. Of the 31 characteristics tabulated for Streptococcus pyogenes and Streptococcus agalactiae 15 of the former and 11 of the latter are indicated as variable or equivocal. This is too many for adequate description and identification of an organism. When these two species are subdivided into varieties, as has been done in the revised table which accompanies this discussion, the number of variable characteristics drops to 5 or les for each variety and the remaining variable characteristics are of a quantitative rather than a qualitative character.

Based upon this revised table, a Key to the Species and Varieties of Groups A, B, C and E of the genus Streptococcus is presented.

\section{KEY TO THE SPECIES AND VARIETIES OF GROUPS A,} $B, C$ AND E OF THE GENUS STREPTOCOCCUS

1. Facultative anaerobic species.

A. Pyogenic group. No growth at $10^{\circ} \mathrm{C}$. or at $45^{\circ} \mathrm{C}$. No growth at $\mathrm{pH} 9.5$. In broth not tolerant of 0.1 per cent methylene blue or 6.5 per cent $\mathrm{NaCl}$.

a. Hippurate -, trehalose + , sorbitol -. All beta hemolytic.

1. Streptococcus pyogenes, Group A.

1.1 Variety pyogenes; mannitol -, salicin + , lactose t.

1.2 Variety infrequens; mannitol $t$, salicin + , lactose $t$.

1.3 Variety scarlatinae; mannitol -, salicin-, lactose t. 
BACTERIOLOGICAL NOMENCLATURE AND TAXONOMY

1.4 Variety alactosus; mannitol + , salicin + , lactose -.

b. Hippurate + , trehalose + , sorbitol -, mannitol -, Group B.

a. Alpha zones in blood agar plates, salicin $t$, lactose + .

2.1 Streptococcus agalactiae var. agalactiae.

b. Small beat zones usually later sur roundedby larger zones of partial hemolysis. Not agglutinated by typing sera prepared against Streptococcus opportunus.

2.2 Streptococcus agalactiae var. mastitidis; salicin $t$, lactose $t$.

2.3 Streptococcus agalactiae var. asalignus; salicin -, lactose t.

c. Zones in blood agar similar to those of Streptococcus agalactiae var. mastitidis. Not agglutinated by typing sera prepared against Streptococcus agalactiae.

3.1 Streptococcus opportunus var.opportunus; salicin t, lactose - .

3.2 Streptococcus opportunus var. pseudomastitidis (n. var.); salicin $t$, lactose + .

c. Hippurate -, trehalose -, mannitol - Beta hemolytic. Group C.

4. Streptococcus equi; sorbitol -, lactose -.

5. Streptococcus zooepidemicus; sorbitol + , lactose +.

d. Hippurate -, trehalose t, sorbitol -, lactose -, Beta hemolytic.

6. Streptococcus equisimilis; Group C.

(Distinguishable from Streptococcus equi by

fermentation of trehalose; from Streptococcus pyogenes var. alactosus $\left(\mathrm{GpA}_{\mathrm{p}}\right) \overline{\text { by failure }}$

to germent mannitol.)

e. Hippurate -, trehalose $t$, sorbitol $t$, mannitol-, salicin $t$, lactose + . Not beta hemolytic. Group C.

7. Streptococcus dysgalactiae.

f. Hippurate $t$, trehalose $t$, sorbitol $t$, mannitol $t$, 
salicin $t$, lactose + .

8. Streptococcus uberis; non-hemolytic.

9. Streptococcus tardus; Group E. Beta hemolytic. Hippurate hydrolysis detectable only by formal titration. 